\title{
CARTOGRAFIAS DO ENVELHECIMENTO EM CONTEXTO RURAL: NOTAS SOBRE RAÇA/ETNIA, GÊNERO, CLASSE E ESCOLARIDADE
}

\author{
CARTOGRAPHIES OF AGING IN THE RURAL CONTEXT: RACE/ \\ ETHNICITY, GENDER, SCHOOLING AND SOCIAL CLASS
}

\begin{abstract}
João Paulo Ferreira (D) (https://orcid.org/0000-0003-0115-9032) ${ }^{1}$, George Leeson (iD) (https://orcid.org/0000-0002-4720-791X) ${ }^{2}$, Vivian Ramos Melhado ${ }^{3}$

${ }^{1}$ Universidade Federal de São Carlos, Departamento de Sociologia, São Carlos, São Paulo, Brasil

<joaopauloferreira@outlook.com>

${ }^{2}$ Universidade Oxford, Instituto de Envelhecimento Populacional, Oxford, Inglaterra, Reino Unido.
\end{abstract}

${ }^{3}$ Universidade Federal de São Carlos, Departamento de Gerontologia, São Carlos, São Paulo, Brasil.

Resumo Este artigo tem como objetivo descrever e analisar as condições sociais gerais referentes à raça/ etnia, gênero, classe e escolaridade, numa amostra de 500 sujeitos ( $\mathrm{n}=250$ homens; $\mathrm{n}=250$ mulheres $)$, com 60 anos e mais, usuários do Sistema Único de Saúde e residentes na zona rural de uma cidade de porte médio, no interior do estado de São Paulo, Brasil, 2015-2016. O desenho é de natureza mista, agrupando técnicas quantitativas e qualitativas, a fim de descrever e analisar interseccionalmente as categorias selecionadas. Para a coleta de dados, foi utilizado um questionário estruturado, com questões fechadas, sobre aspectos sociodemográficos. Com auxílio do software IBM-SPSS (versão 20.0), foi produzido um banco de dados com informações descritivas e específicas. Os resultados obtidos corroboram desigualdades em termos de gênero e raça/ etnia, ao passo que as mulheres autodeclaradas pretas são mais vulneráveis do ponto de vista econômico e de escolaridade, em relação às mulheres autodeclaradas brancas e aos homens autodeclarados brancos ou pretos na mesma faixa-etária. Os dados permitem, por fim, contrapor a tese de que a Constituição de 1988 e suas políticas adjacentes teriam provocado um corte nas desigualdades em termos geracionais.

Palavras-chave envelhecimento rural; gênero; raça; vulnerabilidade social; desigualdade.
Abstract The present article has the goal of describing and analyzing the general social conditions regarding race/ethnicity, gender, social class and schooling among a sample of 500 subjects $(n=250$ men; $\mathrm{n}=$ 250 women), aged 60 years or older, who are users of the Unified Health System (Sistema Único de Saúde, SUS, in the Portuguese acronym) and live in the rural area of a medium-sized municipality in the state of São Paulo, Brazil, between 2015 and 2016. The design of the study is of a mixed nature, combining quantitative and qualitative techniques in order to describe and analyze the selected categories intersectionally. The data was collected using a structured questionnaire with closed questions regarding sociodemographic aspects. With the aid of the software IBM-SPSS (version 20.0), we produced a databank with descriptive and specific information. The obtained results confirm inequalities regarding gender and race/ethnicity, and the women who self-reported as being black are more vulnerable in terms of finances and schooling than the women who self-reported as being white and the men who self-reported as being white or black in the same age group. Lastly, the data enable us to counter the thesis that the 1988 Constitution and its adjacent policies would have provoked an interruption in the inequalities in generational terms.

Keywords rural aging; gender; race; social vulnerability; inequality. 


\section{Introdução}

O envelhecimento populacional no Brasil é marcado por ritmos e fluxos diversos, constituindo processos heterogêneos de velhice. Segundo projeções do Instituto Brasileiro de Geografia e Estatística (IBGE) (2013), a população brasileira deverá crescer até 2042, quando o número de nascidos vivos será ultrapassado pelo número de óbitos. Assim, para 2060, as estimativas indicam que a coorte com 65 anos e mais deverá ser de $26,7 \%$ (58,4 milhões), e a expectativa de vida se aproximará dos 81 anos.

Com o crescimento populacional até meados de 2040 e o consequente prolongamento da longevidade, os tópicos e temas relativos à velhice passaram a figurar não somente como objetos privilegiados de investigação em diferentes áreas do conhecimento nas duas últimas décadas, como também fizeram emergir paradoxos, desafios e dilemas às políticas públicas. De acordo com dados do Censo Demográfico de 2000, por exemplo, constatavam-se diferenças tocantes a gênero na velhice, uma vez que mais de $55 \%$ do contingente populacional com 60 anos e mais era composto por mulheres, e aumenta proporcionalmente em relação à coorte etária. Este fato levou autores de áreas distintas a problematizar sobre a 'feminização' das etapas mais avançadas da vida, o que traz as discussões mais consolidadas em torno do conceito de 'gênero' das ciências sociais à gerontologia (Salgado, 1980; Motta, 1998; Debert, 1999; Camarano, 2003; Almeida et al., 2015).

O conceito de 'raça', por outro lado, pensado como categoria analítica (Hall, 2003), também delineia grupos e estratos populacionais múltiplos, cuja articulação com o conceito de 'gênero' permite entrever variações e matizes a respeito das diferenças sociais sob a perspectiva do envelhecimento. Segundo Camarano (2003), uma das maiores preocupações na velhice provém do fato de que as mulheres com mais de 60 anos apresentam inúmeras vulnerabilidades, quer seja em relação à dependência em decorrência de patologias e aumento das comorbidades, quer seja do ponto de vista econômico e social.

A despeito disso, Motta (1998) e Debert (1999) discutem que a velhice conforma-se de modo distinto para homens e mulheres, ao passo que muitos homens se remetem a este período da vida como o momento de descanso, de tranquilidade econômica, engajamento social em grupos de convivência e em atividades de lazer; algumas mulheres, especialmente as viúvas e aposentadas, passam a experimentar uma nova realidade social, não mais necessariamente restrita ao ambiente doméstico e à esfera do cuidado com a casa e com as obrigações via casamento, ao mesmo tempo em que muitas ainda são vistas como cuidadoras, dividindo a atenção entre a casa, o cônjuge, à assistência e apoio aos pais e demais parentes mais velhos com algum comprometimento físico ou psíquico, à colaboração com o cuidado dos netos etc.

O relatório Síntese de Indicadores Sociais: uma análise das condições de vida da população brasileira, publicado em 2017 pelo IBGE, revelou que uma 
grande parcela dos idosos - categoria que denota homens e mulheres com 60 anos e mais, segundo a Política Nacional do Idoso (1994) - encontrava-se na posição de aposentados. Das razões de rendimento, o relatório evidenciou desigualdades principalmente relativas ao acesso a rendimentos do trabalho, pensões e aposentadoria quando combinadas à origem geográfica, pois há maior vulnerabilidade para a população proveniente das regiões Norte e Nordeste, as quais possuem a menor participação econômica. Essa desigualdade, cambiante de acordo com o território, atinge níveis consideráveis na segmentação por 'raça/etnia', já que em 2016, dentre as pessoas com os $10 \%$ menores rendimentos, pretos ou pardos eram 78,5\%, e brancos 20,8\% (Instituto Brasileiro de Geografia e Estatística, 2016).

Outra forma de medida importante refere-se ao Índice Multidimensional de Pobreza, em que se estabelece uma linha oficial para mensuração, ou muitas delas, como é o caso da metodologia empregada no Brasil e no Canadá (Athias e Oliveira, 2016). Nas últimas duas décadas, no Brasil, foram utilizadas várias linhas para mensuração da pobreza entre a população mais velha, tais como os índices do Programa Brasil Sem Miséria (PBSM) e do Benefício de Prestação Continuada (BPC), os quais também compuseram políticas e leis orçamentárias complementares. O cálculo e as estimativas de rendimento proveniente das linhas apresentam vantagens e inconvenientes; a dificuldade de atualização sistemática das métricas para o rendimento pode tornar o cálculo impreciso e inadequado, notadamente em virtude do aumento ou baixa da inflação e do padrão de vida, além das perdas ou ganhos reais do salário mínimo ao longo do tempo (Instituto Brasileiro de Geografia e Estatística, 2017). Apesar das inúmeras contingências e transformações no cálculo, a medida funciona como um indicador significativo, a nível global, que acompanha pesquisas e relatórios internacionais, como é o caso da Agenda 2030, ${ }^{1}$ formulada pelas Nações Unidas e pelo Banco Mundial em setembro de 2015.

A idade, tomada como critério de medida e alocação de parcelas etárias, representa um marcador de vulnerabilidade e, sobretudo, de desigualdade (Camarano, 2013). Isto nos leva a considerar que a velhice aglutina diferentes representações e realidades quando diluída em meio a outras categorias de diferença social, tais como o 'gênero', a 'raça/etnia' e a 'classe' - compreendida neste artigo segundo o marcador 'renda'.

Neste caminho, o presente artigo dirige seu olhar para sujeitos com mais de 60 anos (homens e mulheres), que vivem atualmente em áreas rurais, no interior do estado de São Paulo, e visa entretecer uma analítica sociodemográfica e comparada a respeito dos indicadores de 'renda', 'escolaridade', 'raça/etnia' e 'gênero'. Nossa hipótese sociológica é de que há desigualdades nos processos de envelhecimento em contexto rural, seguindo o prognóstico das Nações Unidas (2017) e da PNAD Contínua (Instituto Brasileiro de Geografia e Estatística, 2016), o que reverbera num panorama social marcado por vulnerabilidades. 
Por princípio, se entende como problemática a questão da velhice no campo, lançando-se mão das seguintes perguntas: quais seriam os indicadores sociais e as condições sociodemográficas gerais referentes a 'gênero', 'escolarização', 'renda' e 'raça/etnia', entre homens e mulheres com 60 anos e mais, habitantes de áreas rurais? Haveria, interseccionalmente, diferenças entre homens e mulheres com base dados sociodemográficos? Em que medida o perfil racial/étnico constitui (ou não) diferenças e, inclusive, uma medida de vulnerabilidade na população rural?

\section{Percurso metodológico}

A pesquisa contou com desenho quantitativo e qualitativo, que permitiu a combinação de diferentes métodos e técnicas para a coleta e análise dos dados. O estudo foi conduzido no setor de acolhimento e triagem de um hospital federal, localizado numa cidade de porte médio no interior do estado de São Paulo, entre 2015 e 2016. Baseamo-nos em entrevistas estruturadas de uma amostra de 500 sujeitos (homens $=250$; mulheres $=250$ ), com 60 anos e mais, que residiam com a família e eram atendidos pelo Sistema Único de Saúde (SUS). Para o estabelecimento do critério racial/étnico, a pesquisa foi dividida da seguinte maneira: do grupo de homens $(\mathrm{n}=250), 125$ sujeitos se autodenominavam 'brancos' e 125 se autodenominavam 'pretos'. O mesmo foi aplicado para o grupo das mulheres $(\mathrm{n}=250)$, em que 125 se autodenominavam 'brancas' e 125 se autodenominavam 'pretas'.

Para a coleta de dados, aplicamos um questionário com questões sobre características sociodemográficas, como nome, idade, raça/etnia, sexo, nível educacional, endereço e composição da renda. Os dados foram analisados por meio do software IBM-SPSS (versão 20.0), a fim de se obter informações descritivas acerca dos indicadores considerados.

A pesquisa seguiu as recomendações éticas essenciais, tendo sido aprovada, anteriormente à coleta de dados, pelo Comitê de Ética em Pesquisa com Seres Humanos da Universidade Federal de São Carlos ( ${ }^{\circ}$. CAAE: 579881 16.0.0000.5504). As etapas desta pesquisa obedeceram às diretrizes da Resolução 196/96 e 466/2012 do Conselho Nacional de Saúde.

\section{Resultados}

\section{Renda}

A renda predominante entre os dois grupos $(n=250$ homens; $n=250$ mulheres), foi de um salário mínimo - valor relativo à aposentadoria para contribuintes individuais. Na amostra constituída por homens (Tabela 1), a composição das fontes de rendimento variou, de modo que, em termos gerais, 
18 sujeitos relataram exercer trabalho assalariado formal, 42 trabalho informal, 111 sobreviviam com a aposentadoria, 43 com pensão, 17 com o Benefício de Prestação Continuada e 19 com outra(s) fonte(s) de renda. Na amostra formada por mulheres, a composição das fontes de rendimento manteve-se proeminente entre as que declararam sobreviver com a aposentadoria ( $\mathrm{n}=$ 79), mesmo que com significativa redução em termos quantitativos, se comparado ao grupo dos homens ( $=111$; DP: 16); por conseguinte, houve um aumento expressivo relativo à realização de trabalho informal em contraste com os homens, ao passo que 63 mulheres referiram possuir renda oriunda de trabalho informal (DP: 10,5). Também foi possível mensurar um aumento da composição de renda por pensão entre as mulheres (n = 58; DP: 7,5).

Tabela 1

\begin{tabular}{|c|c|c|c|c|c|c|c|}
\hline Variável & $\begin{array}{l}\text { Trabalho } \\
\text { assalariado } \\
\text { formal }\end{array}$ & $\begin{array}{l}\text { Trabalho } \\
\text { informal }\end{array}$ & Aposentadoria & Pensão & $\begin{array}{c}\text { Benefício de } \\
\text { prestação } \\
\text { continuada }\end{array}$ & Outro & Total \\
\hline Homens & 18 & 42 & 111 & 43 & 17 & 19 & 250 \\
\hline Mulheres & 16 & 63 & 79 & 58 & 7 & 27 & 250 \\
\hline Total & 34 & 105 & 190 & 101 & 24 & 46 & 500 \\
\hline Desvio padrão & 1 & 10,5 & 16 & 7,5 & 5 & 4 & \\
\hline \multicolumn{8}{|l|}{ *Homens } \\
\hline $\begin{array}{l}\text { Autodeclarados } \\
\text { pretos }\end{array}$ & 5 & 25 & 49 & 24 & 11 & 11 & 125 \\
\hline $\begin{array}{l}\text { Autodeclarados } \\
\text { brancos }\end{array}$ & 13 & 17 & 62 & 19 & 6 & 8 & 125 \\
\hline Desvio padrão & 4 & 4 & 6,5 & 2,5 & 2,5 & 1,5 & \\
\hline \multicolumn{8}{|l|}{${ }^{*}$ Mulheres } \\
\hline $\begin{array}{l}\text { Autodeclaradas } \\
\text { pretas }\end{array}$ & 5 & 37 & 35 & 25 & 4 & 19 & 125 \\
\hline $\begin{array}{l}\text { Autodeclaradas } \\
\text { brancas }\end{array}$ & 12 & 26 & 46 & 30 & 3 & 8 & 125 \\
\hline Desvio padrão & 3,5 & 5,5 & 5,5 & 2,5 & 0,5 & 5,5 & \\
\hline
\end{tabular}

Fonte: Os autores.

Na divisão por 'sexo' e 'raça/etnia', os dados apontaram para desigualdades substanciais entre os dois grupos. Para o sexo masculino, atribuímos duas variáveis independentes à composição das fontes de rendimento: sujeitos autodeclarados pretos $(n=125)$ e sujeitos autodeclarados brancos $(n=125)$. O mesmo foi aplicado para o grupo de mulheres.

Entre homens autodeclarados brancos, constatamos que uma grande parcela inferiu renda por meio da aposentadoria $(\mathrm{n}=62)$, seguido de pensão $(\mathrm{n}=$ 19), trabalho informal $(n=17)$, trabalho assalariado formal $(n=13)$, outra(s) fonte(s) $(\mathrm{n}=8)$ e recebimento do benefício de prestação continuada $(\mathrm{n}=6)$. Ente os sujeitos autodeclarados pretos, houve diferenças quantitativas, notadamente pela redução relativa no número de sujeitos que inferiram renda por aposentadoria ( $n=49$; DP: 6,5). Por outro lado, houve aumento da composição das fontes de rendimento por trabalho informal ( $n=25$; DP: 4) e diminuição 
do indicador por trabalho assalariado formal ( $n=5$; DP: 4), em contraste com os sujeitos autodeclarados brancos.

O grupo das mulheres, por outro lado, também apresentou diferenças tocantes à composição das fontes de rendimento entre as duas variáveis referentes à 'raça/etnia'. No grupo de mulheres autodeclaradas brancas, nota-se uma predominância nas fontes de renda por aposentadoria $(n=46)$ e pensão $(\mathrm{n}=30)$, renda via trabalho informal $(\mathrm{n}=26)$, trabalho assalariado formal ( $\mathrm{n}$ $=12)$ e, em menor proporção, outra(s) fonte(s) $(n=8)$ e benefício de prestação continuada $(\mathrm{n}=3)$. Em relação às mulheres autodeclaradas pretas, os dados mostram alterações significativas, permitindo corroborar diferenças no perfil de rendimento em relação à 'raça/etnia'; neste aspecto, vê-se um crescimento de rendimento via trabalho informal (n = 25; DP: 4) e uma diminuição do número de trabalhadoras que obtêm renda mediante trabalho assalariado formal ( $\mathrm{n}=5$; DP: 4). Constatou-se também uma diminuição expressiva do número de mulheres que inferiram renda por aposentadoria $(n=49$; DP: 6,5), seguido pelo aumento de pensões ( $\mathrm{n}=24$, DP: 2,5$)$, benefício de prestação continuada (n = 11; DP: 2,5$)$ e outra(s) fonte(s) de rendimento (n = 11; DP: 1,5$)$.

\section{Escolaridade}

No total de sujeitos estudados, 59,4\% ( $\mathrm{n}=297$; DP: 24,5$)$ declararam-se analfabetos, 23,8\% (n = 119; DP: 11,5) com ensino fundamental incompleto, $15 \%$ (n = 75; DP: 10,5) com ensino fundamental completo e 1,8\% (n = 9; DP: $2,5)$ com segundo grau completo. Contudo, quando agrupados pela categoria 'sexo', é possível constatar uma expressiva diferença em termos quantitativos, que reflete indicadores discrepantes entre os quatro níveis de escolaridade mensurados, com as mulheres em posições desiguais, com menos anos de estudo e, consequentemente, maior prevalência de analfabetismo (Tabela 2).

\begin{tabular}{|c|c|c|c|c|c|}
\hline \multicolumn{6}{|c|}{ Indicadores de escolaridade, por sexo e raça/etnia (2013-2015). São Paulo, 2015-2016. } \\
\hline Variável & Analfabeto & $\begin{array}{c}\text { Ensino } \\
\text { fundamental } \\
\text { incompleto }\end{array}$ & $\begin{array}{c}\text { Ensino } \\
\text { fundamental } \\
\text { completo }\end{array}$ & $\begin{array}{l}\text { Segundo grau } \\
\text { completo }\end{array}$ & Total \\
\hline Homens & 124 & 71 & 48 & 7 & 250 \\
\hline Mulheres & 173 & 48 & 27 & 2 & 250 \\
\hline Total & 297 & 119 & 75 & 9 & 500 \\
\hline Percentual & 59,4 & 23,8 & 15 & 1,8 & 100 \\
\hline Desvio padrão & 24,5 & 11,5 & 10,5 & 2,5 & \\
\hline \multicolumn{6}{|l|}{${ }^{*}$ Homens } \\
\hline Autodeclarados pretos & 68 & 38 & 17 & 2 & 125 \\
\hline Autodeclarados brancos & 56 & 33 & 31 & 5 & 125 \\
\hline Desvio padrão & 6 & 2,5 & 7 & 1,5 & \\
\hline \multicolumn{6}{|l|}{${ }^{*}$ Mulheres } \\
\hline Autodeclaradas pretas & 98 & 17 & 10 & 0 & 125 \\
\hline Autodeclaradas brancas & 75 & 31 & 17 & 2 & 125 \\
\hline Desvio padrão & 11,5 & 7 & 3,5 & 1 & \\
\hline
\end{tabular}


Quando se estratificam as amostras por 'sexo' e 'raça/etnia', emergem novos paradoxos e diferenças em relação ao dado geral de escolarização. No grupo constituído por homens, autodeclarados pretos $(n=125)$ e autodeclarados brancos $(\mathrm{n}=125)$, o critério por 'raça/cor' indica que os sujeitos autodeclarados brancos possuem indicadores mais elevados de escolaridade (Tabela 2). Os respondentes autodeclarados pretos, entretanto, apresentaram indicadores mais elevados de analfabetismo ( $\mathrm{n}=68$; DP: 6$)$ e ensino fundamental incompleto ( $\mathrm{n}=38$; DP: 2,5$)$. Porém, houve diminuição referente aos dados para ensino fundamental completo $(\mathrm{n}=17$ : DP: 7$)$ e segundo grau completo $(\mathrm{n}=2$; DP: 1,5). Em suma, os dados revelam que, embora o indicador de 'analfabetismo' seja comumente elevado nas duas amostras, há também diferenças entre as duas variáveis em termos raciais, confirmando que os sujeitos autodeclarados pretos apresentam escolarização inferior aos sujeitos autodeclarados brancos.

No grupo formado por mulheres, há diferenças em relação à variável 'raça/ etnia'. Em mulheres autodeclaradas brancas, houve prevalência de analfabetismo $(n=75)$, seguido por ensino fundamental incompleto, ensino fundamental completo e segundo grau completo. Em contrapartida, mulheres autodeclaradas pretas, aprofundaram as diferenças relacionadas ao analfabetismo, permitindo constatar que as mulheres deste grupo são, majoritariamente, analfabetas (n = 98; DP: 11,5).

Em relação às mulheres autodeclaradas pretas com alguma escolarização, os dados são inferiores àqueles obtidos no grupo de mulheres autodeclaradas brancas -, apenas 17 respondentes relataram possuir ensino fundamental incompleto (DP: 7) e 10 com ensino fundamental completo (DP: 3,5); nenhuma tem segundo grau completo. Assim, é possível verificar distinções entre o perfil de escolarização pelo critério de 'raça/etnia', demonstrando que as mulheres autodeclaradas pretas são, evidentemente, mais vulneráveis.

Comparativamente ao grupo de homens autodeclarados pretos, as mulheres autodeclaradas pretas apresentam também dados inferiores (Tabela 2). Desigualdades por 'sexo' e 'raça/etnia' são mais severas na escolaridade de homens autodeclarados pretos, ao passo que as mulheres autodeclaradas pretas, em todos os cenários possíveis para a população estudada, permanecem com os menores índices de escolarização.

\section{Discussão}

Nasci no Vale do Ribeira, mas me mudei aos 7 ou 8 anos com a família para o interior de São Paulo. Papai e mamãe vieram trabalhar no engenho de café da fazenda Tamoio com um grupo de mais de 50 pessoas. Eu era a mais velha e cuidava de meus sete irmãos [....] Ninguém da minha família foi para a escola. Naquele tempo, 
você sabe, não tinha como; ou a gente trabalhava ou morria de fome. Alguém precisava assumir essa tarefa e tivemos a sorte de não faltar trabalho [...] até a chegada das máquinas. Fui a mais velha dos meus irmãos, e tive de cuidar deles para que mamãe e papai pudessem trabalhar. Depois fui trabalhar nos cafezais, e ainda cuidava da casa e dos meus pais [...]. Só parei de trabalhar quando o médico da colônia me deu uma carta de afastamento por saúde. Naquela época a gente trabalhava até morrer, sabe? Minha mamãe nunca teve problema nenhum de saúde; morreu de uma hora pra outra. A gente acha que foi por recolher muito barbatimão envenenado. Ninguém sabe dizer. (Geralda, 89 anos, autodeclarada preta, imigrante, ex-trabalhadora rural e pensionista).

O relato de campo obtido de Geralda - uma das interlocutoras da pesquisa - e interpretado de modo narrativo para a presente discussão, nos permite compreender qualitativamente os dados produzidos sobre o perfil sociodemográfico encontrado para os dois grupos, de homens e mulheres, em detrimento das categorias 'escolaridade' e 'renda'. A relatada impossibilidade de frequentar a escola na infância e na fase adulta é ilustrativa de praticamente todos os depoimentos e entrevistas. Os resultados atestaram nossa hipótese inicial de que haveria distinções em torno das variáveis 'classe' e 'escolaridade' para homens e mulheres.

A despeito das diferenças relacionadas a gênero, em termos gerais, a população idosa no Brasil representa a coorte populacional mais pobre e com menor índice de escolaridade (Camarano, 2003; Instituto Brasileiro de Geografia e Estatística, 2017), não diferindo muito do que fora relatado pela interlocutora em termos de acesso à educação, tampouco em relação ao próprio Censo Demográfico de 2000. Autores como Silva (1997) e Faleiros (2007) analisam que essa realidade, a qual se apresenta de maneira diversa entre as regiões do país, esbarra ainda em disparidades tocantes ao acesso de recursos fundamentais, como a carência de água tratada, rede de energia elétrica, fonte coletora de esgoto e acesso aos serviços de saúde.

Não obstante, a pesquisa aqui conduzida verte seu olhar para um critério pouco problematizado em relação à literatura gerontológica contemporânea interessada em analisar os processos de velhice e envelhecimento em contexto rural: a 'raça/etnia'. Pelos resultados, vê-se que este critério, como recurso metodológico, delineia um panorama ainda mais problemático e candente às novas pesquisas e à paisagem do envelhecimento no campo. Os dados do Censo de 2000 não discriminavam de modo objetivo as diferenças em termos de 'raça/etnia' entre a população idosa rural autodeclarada preta, parda e branca, prevalecendo dados que focalizavam, sobretudo, na divisão territo- 
rial. A despeito disso, seguimos as proposições de Camarano (2003) relativas a esta lacuna na pesquisa quantitativa, com vistas a estabelecer um diálogo com o Censo de 2010, além da Pesquisa Nacional por Amostras de Domicílio (PNAD), publicada em 2017 pelo IBGE, e que já incorporam informações concernentes à questão da 'raça/etnia' no campo.

A equação meramente territorial entre sujeitos idosos que vivem em áreas urbanas versus os que vivem no campo parece não dar conta de explicar realidades heterogêneas no Brasil, com um histórico processo de discriminação, estigma e escravização da população preta e parda, frequentemente mais pobre e com baixa escolarização (Instituto Brasileiro de Geografia e Estatística, 2000; 2016; 2017).

Neste caminho, a variável 'raça/etnia' corroborou diferenças profundas em relação à composição de renda e escolaridade, que se integra à problemática de gênero, evidenciando que as mulheres com mais de 60 anos e autodeclaradas pretas apresentam menor rendimento e os piores indicadores para educação, nos múltiplos cenários possíveis de comparação. Este dado, em consonância ao que se viu brevemente na introdução, por meio da PNAD Contínua (Instituto Brasileiro de Geografia e Estatística, 2016) e da Síntese dos Indicadores Sociais (Instituto Brasileiro de Geografia e Estatística, 2017), integra uma parcela de sujeitos socialmente vulneráveis, maiormente representada por mulheres pretas e pardas, acima dos 60 anos.

Ainda que haja uma prevalência de mulheres aposentadas $(\mathrm{n}=79)$, os homens apresentam maior proporção de renda relativa à aposentadoria $(\mathrm{n}=111)$. Dito isto, as mulheres, neste contexto, realizam trabalho informal $(n=63)$ na velhice muito mais do que os homens $(n=42)$, a fim de contornar a ausência de seguridade social e conseguir sobreviver. Este dado, aliás, permite reconhecer que as mulheres autodeclaradas pretas $(n=37)$ recorrem mais à esfera informal de trabalho para composição de renda do que as mulheres autodeclaradas brancas $(n=26 ; D P: 5,5)$ na mesma faixa etária.

Em termos históricos, os trabalhadores rurais somente tiveram direito à aposentadoria com a Constituição de 1988. Antes, eram protegidos pelo Funrural, ${ }^{2}$ que lhes garantia poucos benefícios. Portanto, trata-se de uma equiparação tardia em relação aos trabalhadores urbanos. Este fato colaborou para a precarização do trabalhador rural, contribuindo também para um aumento proporcional do número de trabalhadores informais e os chamados boias-frias (ou trabalhadores temporários) (Silva, 1999).

No Brasil e no estado de São Paulo, em particular, em fins dos anos 1960, houve uma emigração do campo para as cidades, em razão da implantação da nova maneira de produzir no campo, cujo resultado foi a expulsão de milhares de famílias de posseiros, colonos, arrendatários e parceiros. As pessoas expulsas no contexto do que se convencionou chamar de 'modernização con- 
servadora' ou 'revolução verde', caracterizadas pelo emprego de tecnologias no campo, dirigiram-se às periferias urbanas. Muitas delas se transformaram em trabalhadores temporários que moravam nas cidades e trabalhavam no campo (Silva, 1999; Stolcke, 1986). Além da expropriação, marca deste processo de 'modernização' das atividades do campo, houve também a migração interna de trabalhadores afluentes de regiões que enfrentavam severas crises econômicas e que não contavam mais com oferta abundante de trabalho, como é o caso da região do Vale do Ribeira nos anos 1970, localizada no Sul de São Paulo, analisada por Silva (1999) e também narrada inicialmente por uma das interlocutoras da pesquisa.

No entanto, segundo Stolcke (1986), muitas famílias e distintos aglomerados populacionais - especialmente os mais velhos em termos etários - persistiram e envelheceram no campo, passando a conviver com os paradoxos da 'modernização' e com os incipientes indicadores de desenvolvimento centrados, historicamente, no baixo rendimento per capita e escolarização.

Do ponto de vista do rendimento, Woortmann \& Woortmann (1999) discutem que o salário obtido por meio da previdência é fundamental para a manutenção das condições básicas de vida, isto é: a compra de medicamentos, alimentação, roupas, instrumentos e utensílios domésticos, principalmente em circunstâncias de extrema seca, desastres ou diminuição da produção rural (sobretudo em situações nas quais as famílias sobrevivem da produção de vegetais orgânicos, animais e outros insumos alimentícios dependentes do solo). Além disso, o salário figura como uma das principais formas de manutenção e reprodução da vida, pois é em consequência dele que se pode estabelecer as condições materiais necessárias para a sobrevivência nas sociedades industrializadas (Marx, 1978; Beauvoir, 1970).

Assim, se o salário por meio de aposentadoria figura como recurso indispensável na ocasião de escassez de trabalho formal e de recursos naturais, adoecimento e mudanças climáticas cujos efeitos impactam diretamente os pequenos produtores rurais e a economia informal proveniente da agricultura familiar, é possível entrever que essa parcela não minoritária de sujeitos desamparados pela previdência encontra-se, em grande medida, em situação de vulnerabilidade social. Além do mais, são pessoas que tiveram suas trajetórias marcadas pela exploração nos extensos aglomerados de cana-de-açúcar, nos pomares de laranja, nas lavouras de soja e nos cafezais, envelhecendo, portanto, com inúmeras comorbidades, em decorrência do trabalho árduo e da precarização das condições de vida no campo no último século (Silva, 1999; 2014; 2016). O surgimento de comorbidades é lugar-comum nos relatos coletados, ao passo que muitos/as interlocutores/as só pararam de trabalhar quando receberam a avaliação médica adequada e foram legalmente amparados por cartas/receituários que atestavam as limitações físico-motoras desenvolvidas. Nota-se, deste modo, que a aposentadoria e a aquisição de pensão por inva- 
lidez se dão num período tardio da vida, em que há déficits significativos e irreversíveis nas atividades básicas e instrumentais da vida diária.

Com base nos questionários foi possível também perceber que praticamente todos os(as) idosos(as) entrevistados(as) haviam realizado trabalho similar ao encontrado na pesquisa de Silva (1999; 2016); isto é, são pessoas que têm suas histórias de vida atreladas à história de trabalho no campo, tendo, em grande medida, a vivência com a mecanização do trabalho e a consequente obsolescência de parte das atividades manuais. O trabalho, como nos alerta Marx (1978), Beauvoir (1970) e Stolcke (1986), é uma categoria complexa, dinâmica e contingente. Não seria possível pensar apenas em perda de função laboral ou cenário reduzido de atuação como meros reflexos da 'modernização do campo' de fins do século XX. Trata-se, evidentemente, de uma remodelação das formas pelas quais as pessoas passam ou deixam de se compreender no mundo, pois o trabalho, como força produtiva que nos interpela objetiva e subjetivamente, é lugar de criação das formas de reconhecimento pessoal e coletivo. Assim, a leitura que se poderia fazer dos resultados, de início, deve-nos provocar sobre essa mudança na maneira de reprodução da vida, notadamente do ponto de vista histórico. A essas mudanças, há um processo contíguo e indissociável relativo à aquisição e ampliação dos direitos sociais no Brasil, por meio da Constituição de 1988.

Com a Constituição de 1988, o sistema previdenciário rural deixa de ser caracterizado prioritariamente por políticas assistencialistas, refratárias do Funrural, com opções e benefícios reduzidos, passando para uma política macro, centrada na proteção social e universal, pelos princípios de cidadania e contando com os mesmos direitos atribuídos aos trabalhadores em contexto urbano.

Por meio das leis 8.212 e 8.213, promulgadas em 1991, modifica-se também a forma como o grupo familiar (marido, mulher e filhos com 16 anos e mais) obtém acesso aos recursos da Previdência Social. Essa mudança passa a integrar todo o conjunto familiar no bojo da política, deixando de ser um recurso exclusivo a uma modesta parcela de sujeitos. Dessa forma, antes das duas leis supracitadas, os trabalhadores rurais tinham direito somente à aposentadoria e pensão por morte, passando a contar, com apoio da Previdência Social, com os mesmos benefícios pagos aos trabalhadores de áreas urbanas, dentre os quais: o auxílio-doença, salário maternidade e a aposentadoria por invalidez. Por fim, outro ponto crucial consistiu na equiparação do piso previdenciário, assegurado pela Constituição, a começar com um salário mínimo comum, nivelando a importância mínima dos benefícios concedidos a trabalhadores rurais e urbanos. ${ }^{3}$

A vulnerabilização da população mais pobre e velha em termos geracionais, pensada sociologicamente, abarca um processo que se iniciou em meados dos anos 1950 no estado de São Paulo, que se iniciou com a substituição das 
fazendas cafeeiras pelas grandes usinas de cana-de-açúcar (Silva, 1999; 2014; 2016). A esse processo:

milhares de camponeses e camponesas deixaram suas terras para o trabalho nos canaviais paulistas. Muitos deixaram a família para trás, como meio de garantia da reprodução social. Aqueles vitimados pela expropriação de suas terras chegaram com as famílias. Esse fato provocou uma mudança no aspecto cromático da classe trabalhadora rural paulista. Não mais estavam em cena os descendentes de colonos europeus e brancos, mas 'a gente dos países do norte', a 'baianada', a 'mineirada', a 'negrada'. Desde seus primórdios, o trabalho nos canaviais caracterizou-se pela precariedade, insalubridade e vulnerabilidade (Silva, 2016, p. 149).

As periferias das cidades canavieiras do estado de São Paulo são habitadas por significativos contingentes populacionais advindos de outras regiões do país e, em muitos casos, este processo caracteriza uma significativa parcela de migrantes negros. No caso da cidade em que se deu a pesquisa, houve a criação de um bairro periférico ${ }^{4}$ em meados dos anos de 1980, por pessoas provenientes de estados do Nordeste, de Minas Gerais, Paraná etc. (Maciel, 2012). Eram camponeses expropriados de suas terras de origem, em consequência da modernização conservadora que atingiu todo o país (Silva, 1999; 2016).

Em relação a isso, segundo Baeninger (1995), a grande região que abrange o território da pesquisa reunia, já nos anos 1970, 75.871 migrantes, cujo montante correspondia a 58.105 egressos do estado São Paulo e 17.766 de outros estados. Baeninger (1995) e Maciel (2012) analisam que o processo migratório intensificou nos anos 1980, 1990 e 2000, levando a população das cidades que compõem a Região de Governo de Araraquara a dobrar de tamanho, de 238.327 para 569.404 habitantes em 2010.

Desde os anos 1950, a taxa de urbanização cresce e, pela primeira vez, a população rural, de 47.958 habitantes, torna-se menor em relação à população urbana, de 50.628 habitantes (Maciel, 2012). Ainda neste caminho, Baeninger (1999) considera que o saldo migratório à região em tela contribuiu com $67,7 \%$ do crescimento absoluto da Região de Governo, isto é, um incremento de 40 mil habitantes. O fenômeno da migração relativo à busca por trabalho e melhores condições de vida nos anos 1960 e 1970 foi clivado pelo componente de 'gênero', ao passo que muitos homens e mulheres - estas geralmente na condição de esposas -, migraram para os antigos assentamentos e às regiões de produção de café, soja, milho, algodão e cana-de-açúcar, desempenhando tarefas igualmente pesadas, insalubres e perigosas ${ }^{5}$. Com o crescimento da modernização agrícola, aliás, houve uma modificação abrupta na antiga estrutura cafeeira, modificando também a estrutura de trabalho e a organização da vida social no campo. Assim, a força de trabalho dos novos 
migrantes somou-se à força dos que já residiam nas áreas rurais do interior do estado de São Paulo (Stolcke, 1986; Silva, 1998; Alves, 1991; Maciel, 2012).

As mulheres, historicamente tolhidas do universo de trabalho assalariado formal (Saffioti, 1976; Goldman, 2011), valeram-se mais de outras estratégias para a composição da renda familiar, quer seja - como já mencionado - por meio da economia informal, quer seja por meio de benefícios federais, como o Benefício de Prestação Continuada. Esse benefício, estabelecido pelo Sistema Único de Assistência Social (Suas), foi criado em dezembro de 1993, com a Lei Orgânica de Assistência Social (Loas), como forma de garantir um salário mínimo a pessoas com 65 anos e mais, bem como a pessoas com deficiência, as quais possuem rendimento familiar per capita abaixo de um quarto de salário mínimo (Alcântara, 2016).

Entretanto, é necessário refletir que as mulheres em situação de vulnerabilidade social no campo desempenharam funções igualmente pesadas e até mesmo mais insalubres do que seus maridos ou parceiros. Isto, pois, segundo Silva (2016), o trabalho feminino é socialmente representado como um trabalho supostamente mais delicado e que incorpora mais cuidado do que aquele desenvolvido por homens. Assim, as mulheres ocupam um papel preponderante no que concerne a trabalhos que exigem, por exemplo, remoção de 'bituca' - recolhimento das canas cortadas pelas máquinas e que estas não conseguem triturar/remover - ' 'abrir o eito' - tarefa empregada para retirar o mato das bordas dos canaviais e nas curvas de nível -, distribuição de herbicidas - que consiste na administração de bombas de veneno de 20 litros cada, nas bordas e nos corredores do canavial -, 'arrancar colonião' - tarefa realizada com enxadão a fim de retirar esse capim chamado de 'colonião' ( $\mathrm{Pa}$ nicum maximum), que brota entre as fileiras de cana e nas bordas e que é de difícil remoção por parte dos herbicidas. (Silva, 2016).

As políticas públicas focalizadas na seguridade, no Brasil, criaram uma situação social distinta a famílias e pessoas que, no passado, estiveram à margem dos rendimentos e do acesso aos serviços, especialmente às mulheres que trabalhavam e ainda sobrevivem do trabalho no campo. A grande mudança, iniciada pela Constituição Federal de 1988, com base nos primeiros escritos sobre seguridade social e velhice, favoreceu e incentivou o surgimento de legislações complementares, como a Política Nacional do Idoso (PNI) em janeiro de 1994, o Estatuto do Idoso em outubro de 2003 e, por último, a Política Nacional de Saúde da Pessoa Idosa em outubro de 2006 (Debert, 1999; Camarano, 2003; Faleiros, 2007; Alcântara, 2016).

Segundo dados do censo demográfico de 1940 e 2000, o contingente feminino acima dos 60 anos respondia a 4,7\% do total da população brasileira em 2000, ante 2,2\% em 1940; a população masculina, também acima dos 60 anos, estava em menor proporção nos anos 2000, perfazendo 3,8\%. Em relação à população considerada 'muito idosa' - formada por sujeitos com 80 
anos e mais - foi de 166 mil pessoas em 1940 para, aproximadamente, 1,8 milhões nos anos 2000. A população feminina 'muito idosa', nos anos 2000, respondia a 12\% desta coorte no Brasil (Faleiros, 2007; Beltrão et al., 2003; Veras, 2009; Alcântara, 2016).

De acordo com Camarano (2003), o retrato da coorte feminina considerada 'idosa' e 'mais idosa' no país é caracterizado pela ausência de experiência no mercado de trabalho formal e pelo baixo índice de escolaridade, constituindo, além disso, piores condições de saúde. Da perspectiva educacional, o IBGE, por meio da PNAD Contínua (Instituto Brasileiro de Geografia e Estatística, 2016), compilou novos dados relativos ao analfabetismo e às diferenças entre raça/etnia na população, iniciando uma série de comparação jamais vista em termos históricos. De acordo com os resultados obtidos, constata-se que pessoas autodeclaradas brancas - em todas as coortes etárias - possuem mais acesso à educação no país do que aquelas autodeclaradas pretas ou pardas, e a população mais velha aglutina o maior contingente de analfabetos, perfazendo 6,07 milhões de pessoas.

Quando se estratifica os dados da PNAD Contínua (Instituto Brasileiro de Geografia e Estatística, 2016) entre sujeitos com 60 anos e mais por raça/ etnia, as diferenças se aprofundam entre brancos, pretos ou pardos. Na coorte composta por sujeitos brancos, o indicador de analfabetismo corresponde a $11,7 \%$, ao passo que o indicador entre pretos e pardos na mesma faixa-etária quase triplica, aproximando-se de 30,7\%.

Este dado engendra aproximações com os resultados obtidos na pesquisa aqui tratada, havendo diferenças de escolarização entre sujeitos autodeclarados brancos e pretos, mas, com um dado inédito - referente à questão de gênero -, em que as mulheres autodeclaradas pretas apresentam os piores indicadores, tanto do ponto de vista da renda quanto da escolaridade, se comparado com os homens autodeclarados brancos e pretos, dentro do mesmo recorte etário. Não obstante, ainda sob este prisma comparativo, as mulheres autodeclaradas pretas referiram composição de rendimento oriunda de aposentadoria, trabalho informal e benefício de prestação continuada, ao passo que os homens foram, proporcionalmente, mais aposentados, com maior experiência no mercado de trabalho formal, além de possuírem indicadores de escolaridade mais elevados. Assim:

as mulheres idosas recebem benefícios em condições menos privilegiadas do que os homens: aposentadoria por idade versus por tempo de serviço e benefícios assistenciais. O valor de tais benefícios é mais baixo. Esta situação reflete a maior precariedade da condição feminina no mercado de trabalho. As formas pelas quais, historicamente, foram se criando adicionais de proteção à mulher em termos previdenciários (menor tempo de trabalho ou contribuição, menor idade para concessão de benefícios, direito à pensão integral para as viúvas) não devem ser vistas apenas 
como compensação pela dupla jornada, mas também pela precariedade das condições de trabalho femininas relativas à masculina (Camarano, 2003, p. 44).

Dos anos 1980 para os anos 2000, o percentual de mulheres sem quaisquer rendimentos teve significativa redução, de $42,2 \%$ para $18,4 \%$, e a proporção de mulheres pobres também diminuiu em 21,3 pontos percentuais, totalizando uma redução de 56\% (Instituto Brasileiro de Geografia e Estatística, 2000; Camarano, 2003). No entanto, contrariando os dados relativos à PNAD/IBGE de 1998, as mulheres na pesquisa aqui conduzida representaram o estrato mais pobre em comparação com os homens, com expressiva redução de rendimentos do marcador de 'raça/etnia', uma vez que as mulheres autodeclaradas pretas estavam em desvantagem comparativamente com os demais grupos (Instituto Brasileiro de Geografia e Estatística, 2000; Camarano, 2003).

Nos estudos de Beltrão et al. (2003) e Camarano (2003), os dados sobre o perfil racial/étnico não apresentaram diferenças significativas em face do rendimento - houve, inclusive, maior proporção de mulheres brancas sem rendimento. Diferentemente, o presente estudo expõe diferenças expressivas à variável 'raça/etnia', e tangencia uma nova proposição empírica e teórica à demografia. Camarano ${ }^{6}$, ainda nesse aspecto, argumenta que - embora não tenha havido diferenças estatisticamente significativas em torno do perfil racial/étnico na pesquisa com os dados do Censo de 2000 - o efeito da categoria 'raça/etnia', de outra maneira, faz-se presente em relação à proporção de mulheres idosas que residem em domicílios considerados pobres; na pesquisa, a autora analisa que pouco mais de $25 \%$ das mulheres pretas e pardas residiam em habitações deste porte.

Ainda sobre as diferenças em torno da composição de rendimentos, mais da metade das mulheres autodeclaradas pretas não possuíam cobertura previdenciária na velhice, o que explica o aumento proporcional de mulheres que realizam trabalho informal - dado semelhante ao que fora encontrado por Camarano (2003) entre mulheres autodeclaradas brancas e pretas nos anos 2000.

A categoria 'trabalho', à luz da pesquisa de Silva (1999; 2014; 2016), torna-se um importante marcador de diferença e reprodução social, uma vez que a divisão sexual do trabalho cria novas desigualdades em relação ao envelhecimento no campo. Segundo Silva (2014; 2016), o 'gênero', a 'classe' e a 'raça/etnia' são conceitos analíticos que devem ser pensados e mobilizados de maneira relacional e dinâmica, pois configuram paradoxos e relações assimétricas, relativas ao modo como o mundo da vida é criado e reproduzido.

Neste aspecto, é preciso apontar que, embora as políticas focalizadas na seguridade social tenham garantido avanços em termos de distribuição de renda, educação e melhora nas condições mais amplas de vida nos últimos trinta anos, há ainda desafios no que diz respeito às diferenças de gênero e 
no perfil racial/étnico da população brasileira com mais de 60 anos que vive em contexto rural.

Guiando-nos pela análise de Brah $(1996 ; 2006)$, por fim, concebemos que as estruturas de 'classe', 'raça/etnia' e 'gênero' não podem ser apreendidas como simplesmente 'variáveis independentes', pois as diferenças e as desigualdades intrínsecas a cada uma delas estão mutuamente imbricadas dentro das outras, e configura-se, portanto, como parte constitutiva. Deste modo, o conceito de 'articulação', primeiramente trabalhado por Stuart Hall (2003, p. 34), tece relações de conexão por meio das quais "as coisas são relacionadas tanto por suas diferenças como por suas semelhanças".

No que concerne às diferenças, vê-se a discrepância do perfil sociodemográfico em termos de escolarização e rendimento, que configura uma situação social distinta entre os grupos analisados, sobretudo no recorte racial e de gênero. Em relação às semelhanças, por sua vez, percebem-se aproximações com os dados oficiais produzidos pelo Censo de 2000, PNAD Contínua (Instituto Brasileiro de Geografia e Estatística, 2016) e pela Síntese dos Indicadores Sociais (Instituto Brasileiro de Geografia e Estatística, 2017), bem como pela literatura especializada. A amostra total ainda é representada pelo espectro do analfabetismo e da baixa profissionalização, que viveram a infância, juventude e parte da fase adulta antes da Constituição Federal (CF) e, portanto, sem garantias legais de direitos. Isso cria um hiato social e econômico entre eles e os sujeitos que nasceram após a promulgação da CF, tendo sua experiência geracional marcada por governos democráticos e políticas sociais centradas na seguridade social, expansão do ensino, crescimento econômico, redução severa da fome e da pobreza extrema, aumento da mobilidade social e dos direitos trabalhistas.

\section{Considerações finais}

É possível concluir, assim, que os marcadores de 'raça/etnia', gênero, renda e escolaridade figuram como importantes ferramentas analíticas para se investigar questões relativas ao envelhecimento rural, como indica Stolcke (1986) e Silva $(1999 ; 2016)$.

Não obstante, o estudo avança do ponto de vista metodológico ao trazer um balanço quantitativo da população idosa rural para uma área central do processo migratório do século passado, e que nos últimos cinquenta anos também vivenciou a 'modernização' de suas atividades laborais de modo abrupto. Sem dúvidas, o projeto nacional de modernizar o campo por meio de máquinas e a transposição dos modos de produzir nos grandes centros criaram uma realidade particular a pessoas e grupos que migraram para estas áreas em meados dos anos 1940 e 1950 e que vivenciaram a obsolescência de suas 
atividades, desemprego e expropriação para as periferias de áreas urbanas próximas (Baeninger, 1999; Maciel, 2012).

O aumento da mobilidade interurbana no Brasil é resultado principalmente de um novo sistema de produção refratário da chamada "agricultura intensiva" (Silva, 2016, p. 260). Nele, o saldo migratório crescente obedece à flexibilização do trabalho nas últimas décadas, ao passo que sujeitos são apropriados e expropriados dentro dos novos modos de produzir e, além disso, são também interpelados de maneira subjetiva, uma vez que o campo torna-se parte essencial da própria vida. Sair do campo em direção às cidades nem sempre é uma questão desejável e estritamente pessoal, o que reforça, ainda, os dilemas em torno do conceito de 'geração', uma vez que são pessoas que viveram grande parte de suas vidas e envelheceram no ambiente rural, apreendendo as relações de trabalho sob o prisma das atividades precárias desempenhada por seus familiares.

Os indicadores produzidos durante a pesquisa nos oferecem, ainda, um retrato relevante e crítico sobre 'renda' e 'escolaridade', servindo também como contraponto para análises que desconsiderem as continuidades em termos de desigualdades sociais após a promulgação da Constituição de 1988 e suas políticas correlatas (PNI e Estatuto do Idoso).

Assim, se as rupturas na forma de produzir no campo criaram uma situação social distinta a diversos aglomerados populacionais (migrantes e não migrantes) atualmente acima dos 60 anos e que vivem em áreas rurais, as novas políticas e legislações emergidas da Constituição teriam tido um saldo positivo a esta coorte em termos sociodemográficos? Em primeiro lugar, poderíamos dizer que não. Há, evidentemente, um saldo positivo sobre o trabalho assalariado formal para homens e mulheres. Entretanto, é possível afirmar que as mulheres ainda desempenham mais trabalho informal comparativamente aos homens, além de serem menos assistidas pela política da previdência social, elas somente obtêm tal recurso via pensão e somente após o falecimento do cônjuge - portanto, de modo tardio.

Em segundo lugar, conclui-se que tanto homens quanto mulheres possuem baixos indicadores de escolarização, o que assinala uma permanência em termos históricos com os indicadores sociais do país anteriores à Constituição, PNI e Estatuto do Idoso (Censo Demográfico, 2000). Os dados coletados, em diálogo com as recentes publicações do IBGE - em especial as do Censo Demográfico de 2010 e da PNAD Contínua (2017) -, por fim, nos permitem questionar o postulado de que haveria supostamente uma 'descontinuidade' celebrada com base nestas três políticas (Constituição, PNI e Estatuto do Idoso) em relação à população idosa rural no Brasil. O que nos parece apropriado considerar, entretanto, é que há permanências, muito mais do que descontinuidades, quando investigamos tais indicadores do ponto de vista 'racial/étnico' e de 
'gênero', e que prevalece um retrato de velhice já imaginado, de rarefação dos direitos se mulher e de origem 'racial/étnica' preta.

\section{Agradecimento}

Ao Conselho Nacional de Desenvolvimento Científico e Tecnológico (CNPq), ao Fundo Lesley Kirkley e ao Instituto de Envelhecimento Populacional da Universidade de Oxford, pelo financiamento e colaboração com a pesquisa. À Professora Doutora Maria Aparecida de Moraes Silva, da Universidade Federal de São Carlos, pela revisão crítica e pelas considerações teóricas.

\section{CARTOGRAFÍAS DEL ENVEJECIMIENTO EN EL CONTEXTO RURAL: RAZA/ETNIA, GÉNERO, ESCOLARIDAD Y CLASE SOCIAL}

Resumen Este artículo tiene como objetivo describir y analizar las condiciones sociales generales referentes a la raza/etnia, género, clase y escolaridad, en una muestra de 500 sujetos $(n=250$ hombres; $\mathrm{n}=250$ mujeres), con 60 años o más, usuarios del Sistema Único de Salud y residentes en la zona rural de una ciudad de tamaño medio, en el interior del estado de São Paulo, Brasil, 2015-2016. El diseño es de naturaleza mixta, agrupando técnicas cuantitativas y cualitativas, a fin de describir y analizar interseccionalmente las categorías seleccionadas. Para la recogida de datos se utilizó un cuestionario estructurado con preguntas cerradas sobre aspectos sociodemográficos. Con la ayuda del software IBM-SPSS (versión 20.0) se generó una base de datos con información descriptiva y específica. Los resultados obtenidos corroboran desigualdades en términos de género y raza/etnia, al ritmo que las mujeres autodeclaradas negras son más vulnerables desde el punto de vista económico y de escolaridad en relación a las mujeres autodeclaradas blancas y a los hombres autodeclarados blancos o negros de la misma franja de edad. Por último, los datos permiten hacer frente a la tesis que establece que la Constitución de 1988 y sus políticas adyacentes habrían provocado un corte en las desigualdades en términos generacionales.

Palavras clave envejecimiento rural; género; raza; vulnerabilidad social; desigualdad.

\section{Notas}

${ }^{1}$ A Agenda 2030 tem como foco principal a erradicação da pobreza em diferentes dimensões e formas, especialmente a pobreza extrema, buscando alternativas de desenvolvimento sustentável. O texto propõe 17 Objetivos de Desenvolvimento Sustentável e 169 metas, com vistas a abranger uma agenda universal. Os novos objetivos e as metas se baseiam nas proposições dos Objetivos de Desenvolvimento do Milênio (ODM), realizada pelo Programa das Nações Unidas para o Desenvolvimento (PNUD) em setembro de 2000, ampliando e universalizando seu escopo.

2 Fundo de Assistência ao Trabalhador Rural.

3 Disponível em: http://www.normaslegais.com.br/trab/lprevidenciarial41008.htm Acesso em: 22 jan. 2018. 
4 O processo de expansão da cidade, somado à especulação imobiliária e ao esgotamento do território urbano, resultou na formação do bairro Cidade Aracy. De acordo com Maciel (2012, p. 22), “esse território é composto por quatro bairros Cidade Aracy I, Cidade Aracy II, Presidente Collor e Antenor Garcia, divididos pelo Censo 2010 (Instituto Brasileiro de Geografia e Estatística, 2010) em quinze setores censitários totalizando uma população de 19.079 habitantes. Estes bairros estão inseridos no subdistrito de Bela Vista que concentra 66.988 habitantes".

${ }^{5}$ Na pesquisa de Silva (2016, p. 156-157), empreendida na mesma região que estamos abordando neste artigo, recupera a divisão sexual do trabalho no campo. A autora discute sobre o caráter insalubre, pesado e invisível das tarefas realizadas por mulheres; a saber: administração de herbicidas, recolhimento da cana triturada pelas máquinas, remoção dos matos nas bordas dos canaviais, plantio de novas mudas de cana e o recolhimento de pedras.

\section{Referências}

ALCÂNTARA, Adriana. Envelhecer no contexto rural: a vida depois do aposento. In: ALCÂNTARA, Alexandre O.; CAMARANO, Ana A.; GIACOMIN, Karla C. (Orgs.). Politica Nacional do Idoso: velhas e novas questões. Rio de Janeiro: IPEA, 2016. p. 323-342.

ALMEIDA, Alessandra V. et al. A feminização da velhice: em foco as características socioeconômicas, pessoais e familiares das idosas e o risco social. Textos \& Contextos. Porto Alegre, v. 14, n. 1, p. 115-131. 2015.

ALVES, Francisco J. C. Modernização da agricultura e sindicalismos: luta dos trabalhadores assalariados rurais da região canavieira de Ribeirão Preto. 1991. 347 f. Tese (Doutorado) - Universidade Estadual de Campinas, Campinas, 1991.

ATHIAS, Leonardo.; OLIVEIRA, Leonardo. Indicadores de padrão de vida e distribuição de renda. In: SIMÕES, André.; FRESNEDA, Betina. (Orgs.). Panorama nacional e internacional da produção de indicadores sociais. Rio de Janeiro: IBGE, Coordenação de População e Indicadores Sociais, 2016. p. 110-157.
BAENINGER, Rosana A. Região, metrópole e interior: espaços ganhadores e espaços perdedores nas migrações recentes - Brasil, 1980-1996. 1999. $234 \mathrm{f}$. Tese (Doutorado) - Universidade Estadual de Campinas, Campinas, 1999.

BEAUVOIR, Simone. La Vieillesse. Paris: Gallimard, 1970.

BELTRÃo, Kaizô I. et al. Desigualdades que perduram: probabilidade de acesso a benefícios previdenciários por sexo e raça/cor. Rio de Janeiro: mimeo, 2003.

BRAH, Avtar. Cartographies of diaspora: contesting identities. Routledge: London, 1996.

BRAH, Avtar. Diferença, diversidade, diferenciação. Cadernos Pagu. Campinas, v. 26, p. 329-376. 2006.

CAMARANO, Ana A. Mulher idosa: suporte familiar ou agente de mudança? Estudos Avançados. São Paulo, v. 17, p. 17-35. 2003.

DEBERT, Guita G. A reinvenção da velhice: socialização e processos de reprivatização do envelhecimento. São Paulo: EDUSP, 1999. 
FALEIROS, Vicente P. Cidadania: os idosos e a garantia de seus direitos. In: NERI, Anita L. (org.). Idosos no Brasil: vivências, desafios e expectativas na terceira idade. São Paulo: Editora Fundação Perseu Abramo, 2007. p. 153-167.

GOLDMAN, Emma. Tráfico de mulheres. Caderno Pagu, Campinas, SP, v. 11, n. 37, p. 247-262, 2011.

HALL, Stuart. Da diáspora: identidades e mediações culturais. Belo Horizonte: Editora da UFMG, 2003.

INSTITUTO BRASILEIRO DE GEOGRAFIA E ESTATÍsTICA. Censo demográfico, 2000.

\section{INSTITUTO BRASILEIRO DE GEOGRAFIA} E ESTATÍsTICA. Censo demográfico, 2010.

INSTITUTO BRASILEIRO DE GEOGRAFIA E ESTATÍSTICA. Síntese de indicadores sociais: uma análise das condições de vida da população brasileira, Rio de Janeiro: IBGE, 2016. (Estudos e pesquisas. Informação demográfica e socioeconômica; n. 36).

INSTITUTO BRASILEIRO DE GEOGRAFIA E ESTATÍSTICA. Sintese de indicadores sociais: uma análise das condições de vida da população brasileira, Rio de Janeiro: IBGE, 2017. (Estudos e pesquisas. Informação demográfica e socioeconômica; n. 37).

Instituto Brasileiro de Geografia e Estatística. Coordenação de População e Indicadores Sociais. Gerência de Estudos e Análises da Dinâmica Demográfica. Projeção da população do Brasil por sexo e idade para o período 2000-2060, ago. 2013.

MACIEL, Lidiane M. O sentido de melhorar de vida: arranjos familiares na dinâmica das migrações rurais-urbanas em São Carlos-SP. 2012. 164 f. Dissertação (Mestrado em Sociologia)- Universidade Estadual de Campinas, Campinas, 2012.

MARX, Karl. Le capital. Paris: Éditions Sociales, 1978.
MOTTA, Alda B. Chegando pra idade. In: BARROS, Myriam L. (org.). Velhice ou terceira idade? Rio de Janeiro: FGV, 1998. p. 223-235.

SAFFIOTI, Heleieth. A mulher na sociedade de classe: mito e realidade. Petrópolis: Vozes, 1976.

SALGADO, Marcelo A. Velhice, uma nova questão social. São Paulo: SESC, 1980.

SEN, Amartya K. Inequality re-examined. Oxford: Clarendon Press, 1992.

SILVA, Maria A. M. Errantes do fim do século. São Paulo: Edunesp, 1999.

SILVA, Maria A. M. A nova morfologia do trabalho nos canaviais paulistas. In: ANTUNES, Ricardo (Org.). Riqueza e miséria do trabalho no Brasil III. São Paulo: Boitempo, 2014. p. 279-300.

SILVA, Maria A. M. Trabalho rural: as marcas da raça. Lua Nova:Revista de Cultura e Política, São Paulo, v. 99, p. 139-167, 2016.

SILVA, José G. O novo rural brasileiro. Nova Economia, Belo Horizonte, v. 7, n. 1, p. 43-81, 1997.

STOLCKE, Verena. Cafeicultura. Homens, mulheres e capital (1850-1980). São Paulo: Brasiliense, 1986.

UNITED NATIONS. Sustainable development goals. New York: UM, 2017.

VERAS, Renato. Envelhecimento populacional contemporâneo: demandas, desafios e inovações. Revista de Saúde Pública, São Paulo, v. 43, p. 548-554, 2009.

WOORTMANN, Ellen; WOORTMANN, Klaas. Velhos camponeses. Revista Humanidades, Fortaleza, v. 46, p. 132-141, 1999. 